\title{
Community outcomes of occupational therapy service learning engagements: perceptions of community representatives
}

Elize Janse van Rensburg, B Occ Ther (UFS), M Occ Ther (UFS) https://orcid.org/0000-0002-7232-0690 Lecturer, Department of Occupational Therapy, University of the Free State

Tania Rauch van der Merwe, B Occ Ther (UFS), M Occ Ther (UFS) https://orcid.org/0000-0002-575 I-2707 Lecturer, Department of Occupational Therapy, University of the Free State

Mabel A Erasmus, BA (PU), BA Hons (UP), MA (UP), PhD (PU for CHE) https://orcid.org/0000-0003-3235-447I Associate Professor (Retired), Higher Education Studies, University of the Free State

Background: Service learning is used as an educational approach in many undergraduate occupational therapy programmes in South Africa and the rest of the world. Evidence for the impact of occupational therapy service learning engagements in communities, from the perspectives of community partners, is limited.

Aim: The purpose of this study was to describe the perceptions of community representatives regarding the outcomes of occupational therapy service learning engagements.

Methods: A descriptive qualitative enquiry design was used. In-depth interviews were conducted with eight purposively sampled community representatives and analysed using inductive qualitative content analysis.

Results: This paper reports on the theme related to community outcomes of occupational therapy that emerged from the data, consisting of seven categories, namely: (I) increased knowledge and skills, (2) attitudinal change leading to practice reform, (3) increased access to resources and infrastructure, (4) enhanced community connections, (5) enhanced confidence and dignity, (6) enhanced occupational participation, and (7) non-realisation of partnership goals.

Conclusion: The findings of the study demonstrated that although there were some instances in which partnership goals were not realised, occupational therapy service learning engagements contributed to occupational enablement, occupational justice, health and well-being for community members.

Key words: Service learning; occupational enablement; community engagement; community-based practice; community-based education

\section{INTRODUCTION}

From its inception in $1943^{\prime}$ South African occupational therapy training programmes have utilised forms of community-based education. Service learning, a community-based educational strategy that is situated within a reciprocal partnership context and aimed at addressing community goals and enhancing student learning was only employed from the 2000's in occupational therapy curricula ${ }^{2}$. This coincided with the implementation of service learning in South African higher education through the triad Community - Higher Education - Service Partnerships (CHESP) initiative ${ }^{3}$. In this short time, service learning engagements emerged in many communities across South Africa, and publications on service learning in occupational therapy proliferated ${ }^{4,5}$.

The primary focus of most of the initial publications on service learning was on investigating and establishing service learning as a valid pedagogy. As a result, the educational effects of service learning on students, have been widely researched, bearing mostly positive results ${ }^{6,7}$. However, evidence for the impact of occupational therapy service learning engagements in communities, from the perspectives of community partners, is limited ${ }^{8}$. The characteristic that distinguishes service learning from other community-based educational approaches is the reciprocal nature of the partnership 9 . Although it is assumed that by its nature, service learning will benefit communities through collaborative curriculum design with communities as partners, there is little empirical evidence to support these assumptions ${ }^{10}$.

Service learning as an educational approach is occasionaly criti- cised for its potentially high resource and time cost, limitations in terms of applicability across disciplines and diverse student groups. Reeb and Folger ${ }^{8}$ indicate that there are still significant limitations to existing literature on community outcomes of service learning, including that studies are not guided by theory and lack methodological rigour. They extrapolated "conclusions about community outcomes of service learning must be viewed as preliminary" 8:402. In addition to the lack of methodologically sound evidence regarding the outcomes of service learning in communities, South African authors ${ }^{11,12}$ bemoan the fact that the views and perceptions of communities in service learning engagements remain largely unexamined.

This article puts forward the argument that in a collaborative endeavour such as service learning, the perspectives of stakeholders on what constitutes 'successful outcomes' are pivotal in understanding the effect of ccupational therapy service learning engagements in communities. The article aims to report on the outcomes of occupational therapy service learning engagements at a South African University from the perspectives of community representatives. This aim emanates from research done for a master's degree and relates to one theme derived from the larger study ${ }^{13}$.

\section{LITERATURE REVIEW}

Bringle and Steinberg ${ }^{14}$ point out that studies conducted on the community outcomes of service learning tend to focus on contribution to quality of life in communities, or on relationships between the community and other stakeholders. Others ${ }^{9}$ critique that research in service learning tends to conflate community outcomes with 
analyses of partnerships. To avoid these pitfalls, this literature review focuses on international, local and discipline-specific evidence for the outcomes of service learning engagements.

Reeb and Folger' $s^{8}$ international review of studies investigating the community outcomes of service learning, illuminated three areas of benefit to communities through service learning: satisfaction with service learning students and their work, experiencing student services as helpful, and facilitation of partnerships between communities and universities. Challenges they identified involved difficulties with student schedules, a lack of communication between stakeholders, and short-term projects as opposed to long-term commitments ${ }^{8}$. Bringle and Steinberg ${ }^{14}$ note that benefits drawn from student involvement outweigh costs such as time and resources invested in students. South African studies on service learning from the perspective of community partners yielded similar evidence to international studies. Benefits were community members' positive perceptions regarding student work and increased knowledge and skills. Challenges identified were a lack of understanding of the purpose of service learning activities, and poor communication with community members ${ }^{11,12}$.

In occupational therapy service learning literature there are a number of studies that report on the impact of specific service learning programmes. These studies made use of measures such as the Canadian Occupational Performance Measure (COPM) ${ }^{15}$ and self-report scales ${ }^{16,17}$, analyses of course documents such as community partner feedback forms, e-mails and interviews ${ }^{18}$ to evaluate community outcomes. Some studies reporting on community outcomes also make use of student or lecturer evaluations of community outcomes ${ }^{16}$. Congruent with literature in other fields, these studies generally report satisfaction with student service and positive outcomes for community members (e.g. improved satisfaction scores on the COPM ${ }^{15}$ ). However, there remains an apparent lack of rigorous prospective studies into the outcomes of service learning in occupational therapy from the perspectives of communities.

Service learning partnership goals are collaboratively negotiated and designed with communities ${ }^{19}$. The nature of activities that take place within service learning engagements are diverse and consequently, so are the potential outcomes. In addition, students also have to benefit from service learning activities and the goals of engagements have to fall within the scope of practice of the occupational therapy profession. This required a focus on occupation as the profession's domain of concern ${ }^{20,21}$ and enablement as the core competency ${ }^{22,23}$. 'Enabling occupation' was therefore viewed as the overarching intended outcome of occupational therapy ser- vice learning engagements. Townsend et al. ${ }^{23: 99}$ describe enabling occupation as:

"[The] processes of facilitating, guiding, coaching, educating, prompting, listening, reflecting, encouraging, or otherwise collaborating with people so that individuals, groups, agencies or organisations have the means and opportunity to participate in shaping their own lives; enabling is the basis of occupational therapy's client-centred practice and a foundation for client empowerment and justice...."

This view necessitated methodological consideration that would allow rigorous investigation of the intended outcomes of occupational therapy service learning engagements, from the perspective of the community representatives.

\section{METHODOLOGY}

The study was positioned in a constructivist paradigm and utilised a descriptive qualitative enquiry design ${ }^{24}$ within a larger qualitative study.

\section{Research setting}

This study was conducted at one South African university that offers a professional baccalaurean degree in occupational therapy. Service learning is utilised as a teaching method in the undergraduate occupational therapy curriculum in each of the four study years, with different learning outcomes for each year group. At the time that the study was conducted, the occupational therapy department had active service learning engagements with eleven service learning sites of which seven were located in urban areas and four in rural areas. Students from different year groups were placed at different sites, although some sites accommodated students from various year groups (Table I below). Seven of the service learning sites were included in the study, as four of the sites did not comply with the sampling criteria, or did not consent to participate.

Entry into the respective service learning sites was facilitated by the occupational therapy department's service learning coordinator.

\section{Participants}

Community representatives at each of the service learning sites were approached for participation in the study. A 'community representative' was defined as someone:

I. who is a member of the community where services are rendered through service learning,

2. who was appointed by the community or community organisation to act as a 'gatekeeper' to the particular community,

3. who acts as a collaborator with the university, and

Table I: Structure of service learning placements at the time of the study

\begin{tabular}{|c|c|c|c|c|c|}
\hline Site & Rural / Urban & Type of organisation & $\begin{array}{l}\text { Student year group } \\
\text { involved in service } \\
\text { learning at time of study }\end{array}$ & $\begin{array}{c}\text { Duration of } \\
\text { service learning } \\
\text { partnership }\end{array}$ & Participation \\
\hline I & Urban & Residential Care Facility & $2^{\text {nd }}$ & 5 years & Included in study \\
\hline 2 & Urban & Residential Care Facility & $I^{\text {st }}$ & 4 years & $\begin{array}{l}\text { No eligible community representative } \\
\text { to participate }\end{array}$ \\
\hline 3 & Urban & Residential Care Facility & $I^{\text {st }}$ & 2 years & Included in study \\
\hline 4 & Urban & Child Day Care Centre & $\left.\right|^{\text {st }}$ & 5 years & Included in study \\
\hline 5 & Urban & Child Day Care Centre & $2^{\text {nd }}$ & 2 years & Included in study \\
\hline 6 & Urban & Youth Centre & $2^{\text {nd }}$ & I year & $\begin{array}{c}\text { Duration of partnership did not allow } \\
\text { inclusion }\end{array}$ \\
\hline 7 & Urban & Residential Care Facility & $1^{\text {st }} \& 2^{\text {nd }}$ & 5 years & Did not consent to participate \\
\hline 8 & Rural & Public High School & $3^{\text {rd }} \& 4^{\text {th }}$ & 5 years & Included in study \\
\hline 9 & Rural & Public Primary School & $3^{\text {rd }} \& 4^{\text {th }}$ & 5 years & $\begin{array}{l}\text { No eligible community representative } \\
\text { to participate }\end{array}$ \\
\hline 10 & Rural & Residential Care Facility & $3^{\text {rd }} \& 4^{\text {th }}$ & 5 years & Included in study \\
\hline II & Rural & Public Intermediate School & $3^{\text {rd }} \& 4^{\text {th }}$ & 5 years & Included in study (two participants) \\
\hline
\end{tabular}


4. who represents the community members who are recipients of the services rendered through service learning.

Non-probability, purposive sampling ${ }^{24}$ was utilised to identify community representatives who would be eligible to participate in the study. The following eligibility criteria were set in addition to the operational definition of a community representative:

I. The community representative must have been involved with the occupational therapy service learning engagement for a minimum of two years. They must have had contact with university staff and students, at least once per semester, to ensure that they have sufficient exposure to student service activities, and the observable outcomes thereof in order to construct perceptions in this regard.

2. Community representatives of all cultural and language groups were included in the study. A trained interpreter was offered to all participants who were not English or Afrikaans first language speakers, if they preferred to conduct the interviews in another language. One participant requested for the interview to be conducted with an interpreter.

3. Community representatives were excluded from the study if they were formally employed by the university as this could have caused a conflict of interest and compromised the trustworthiness of the data.

Eight community representatives from seven different service learning sites complied with the sampling criteria and gave voluntary informed consent to participate in the study.

\section{Data collection}

Data were collected through in-depth interviews, conducted at the respective service learning sites by the first author. All service learning sites were visited at least twice prior to conducting the interviews in order to establish rapport with participants and to make practical arrangements for the interviews. The interview schedule comprised thirteen questions in total, of which four related directly or indirectly to the outcomes of the service learning engagements - the four questions related to outcomes are listed in Table II (below). The average duration of the interviews was one hour.

\section{Table II: Interview question and probes related to outcomes of occupational therapy service learning engagements}

\section{Opening question:}

Tell me about your service learning partnership with the university?

\section{Follow-up questions:}

- What have you been striving to achieve in the community through the service learning engagement with the university? To what extent has this happened?

- In your opinion, what has changed in the community since you have entered into the service learning engagement with the university?

- What has been the biggest success / value / contribution / outcome of the service learning engagement?

Interviews were recorded with digital voice recorders, and recordings were transcribed by a professional transcriber. Inductive qualitative content analysis of transcriptions ${ }^{25}$, utilising manual descriptive coding ${ }^{26}$, was done independently by the first and second authors and a third co-coder as a manner of investigator triangula$\operatorname{tion}^{27,28}$. Following independent coding and synthesis of the data into codes, categories and themes, coders collaborated regarding their respective findings in order to construct the preliminary findings.

The first author then returned to study participants to conduct participant verification of the preliminary findings in order to enhance the trustworthiness of this study ${ }^{27,29}$. Utilising resources such as an explanatory thematic analysis sheet and an infographic poster, the interpreted findings of the study were discussed with participants in depth. Participants were then afforded the opportunity to give feedback on the researchers' interpretations of the findings and this feedback was incorporated into the final findings of the study.

\section{Considerations regarding ethics and trustworthiness}

The study was approved by the Health Sciences Research Ethics Committee of the University of the Free State (ethical clearance number: ECUFS 2I3/20I2). Participants gave written, voluntary informed consent to participate in the study. Participants in research are usually not named, in order to protect their identities. However, participants in this study were given the choice whether they wanted to be acknowledged for their contributions by name. This was done partly to acknowledge the reciprocal nature of knowledge creation within service learning engagements.

Trustworthiness of the study was enhanced through investigator triangulation during coding, participant verification, negative case analysis, keeping an audit trail of evidence, and doing a literature control of interpreted findings ${ }^{27,29}$.

\section{RESULTS AND DISCUSSION}

This paper reports on findings related to the outcomes of service learning which emanated from the larger study ${ }^{13}$ on community representatives' perceptions about occupational therapy service learning engagements. Due to the varied nature of service activities at the respective service learning sites, the outcomes of service learning is also expected to be varied ${ }^{30}$. Common trends in community participants' experiences of occupational therapy service learning outcomes were, however, identified. The theme comprised of seven categories, namely (I) increased knowledge and skills, (2) attitudinal change leading to practice reform, (3) increased access to resources and infrastructure, (4) enhanced community connections, (5) enhanced confidence and dignity, (6) enhanced occupational participation and (7) non-realisation of partnership goals.

\section{Increased knowledge and skills}

Service activities performed by students in communities often involved training strategies, evidencing the adoption of the role of 'trainer' or 'educator' as one of the roles of the occupational therapist in the community in these service learning engagements ${ }^{31}$. Community representatives expressed how these training strategies led to outcomes of increased knowledge and skills:

[The students] come here, talk with them [the teachers]. They train them and they did tell them how to do it or how to handle the kids. And then they [the teachers] ... take that information and use it. And then it works.

The development of knowledge and skills through training is a common need from communities in relation to service learning 11,32 ; perhaps because knowledge is viewed as the university's primary commodity. Brower ${ }^{33: 60}$ elucidates the need for training by identifying it as a way to address immediate felt needs, and thus extrapolating "provi[sion] for immediate needs through training and resources" as the first principle for sustainable development through service learning. Participants in this study expressed a need for training as a priority in service learning engagements, and shared their experiences of the enabling effects that training had in their communities as increased knowledge and skills in dealing with challenges that they face.

\section{Attitudinal change leading to practice reform}

Participants noted that service learning activities contributed to changes in attitudes (labelled 'attitudinal change'). Changes in attitudes in turn lead to a change in the way things were being done (labelled 'practice reform'). Participants mentioned various stakeholders who had demonstrated changes in attitudes and ways of doing. These stakeholders included community representatives themselves, community organisation staff, community organisa- 
tion management teams and community members. As a result of service learning endeavours, changes in organisational policies and the implementation thereof had taken place. This seemed to have contributed to countering occupational injustices such as occupational deprivation ${ }^{34}$ in a residential care facility:

...and then the Management heard [about the training] ... and [it made a difference] in the sense that we [now] want to make it more homely for the elderly. For example, we have breakfasts - for the people who are able, they don't have to come and eat breakfast at a certain time. Took away that routine a little bit. .... We arranged a tearoom for them. They can make their own tea. So it creates a bit more of a homely atmosphere for the elderly. ... Not this routine and institution directed care anymore.

In this residential care facility, part of the service learning activities entailed training opportunities for management, staff, and familiy members on the use of person-centered care. This led to a change in attitudes away from institution-directed care towards more person-centered care. Practical changes (such as the flexible breakfast times and tearoom) were done by the management and staff members of the residential care facility themselves in response to attitudinal changes resulting from service learning engagements. Through these changes, the residents of the residential care facility were afforded renewed opportunities for social engagement, and to participate in meaningful occupations, such as making their own tea in a more homely environment.

These findings provide some evidence that service learning endeavours contributed to change, albeit small, in the community. Change is one of the foundations of occupational enablement, targeting occupational participation, health, well-being and occupational justice ${ }^{23}$. The findings that were presented in this category relate to changes in occupational participation - that is, how community members participated in their daily life occupations such as teaching, caring and relating to others, as well as changes in occupational justice.

\section{Increased access to resources and infrastructure}

Participants perceived service learning engagements to enhance their access to resources and infrastructure. Resources included both tacit resources, such as information, and tangible resources, such as information leaflets and posters, assistive devices for elders that had suffered strokes, learning materials for a crèche, and sewing kits following a sewing skills development project at a high school special education class. These resources, in turn, enabled community members to continue working towards their goals in the absence of students as expressed by one participant:

And they left things behind for us. Like the pictures on our [points to poster] every teacher received a healthy balance lifestyle leaflet that we [use] every time - because I teach LO [Life Orientation], I refer back to it. And then we remember. For example, 'Physical', what did the students do again? And then we sing the song.

Suarez-Balcazar et al. ${ }^{35}$ also note enhanced access to tangible resources as a possible benefit to communities resulting from occupational therapy service learning engagements. Delivering tangible resources seems to contribute to enablement in general (e.g. by providing something to refer back to), and enabling occupation specifically (e.g. in the case of providing needed assistive devices for occupational performance). However, where a continued need for resources exists (e.g. in the provision of assistive devices), careful negotiation and planning is necessary to ensure that resources will be accessible even when the service learning engagement ends. It is here that other outcomes, such as enhanced community connections, play an important role. By facilitating connections with other community stakeholders who are able to contribute with the delivery of needed resources, honouring agency, and sustainability of the positive effect of tangible resources can be enhanced.

In addition to tangible resources, infrastructure development was also mentioned as an outcome of service learning activities.
Examples of infrastructure development done through service learning included sensory rooms and gardens, painted chess boards on cement surfaces at a school and structural environmental adaptations to a living room in a residential care facility.

Findings related to infrastructure development were, however, particularly divergent depending on what transpired. On the one hand, it contributed to addressing real needs ensuring stakeholder buy-in and enhancing carry-over. On the other hand, infrastructure development that was not accompanied by the appropriate maintenance strategies or that was not appropriately designed to the needs and realities of the community, was perceived as detrimental to occupational enablement.

Communities often view universities as resource-rich ${ }^{32}$, and in South Africa, extension of university resources to under-resourced communities is an explicit driver of service learning on a policy level $^{3}$. Resource sharing and infrastructure development provides a means for universities to make a meaningful material contribution to under-resourced community areas through service learning. Under the right circumstances, resource sharing and collaborative infrastructure development can contribute to sustainability of service learning engagements. However, it is pivotal to pay specific attention to collaboratively designing infrastructure with, and tailored to, the needs and realities of the community, and implementing a feasible maintenance strategy to ensure that infrastructure development does indeed contribute to occupational enablement in communities.

\section{Enhanced community connections}

Participants articulated that service learning engagements made a significant contribution in terms of facilitating greater community connections, which in turn enhanced the continuity and sustainability of endeavours that originated within the service learning engagement. One participant expressed it as follows:

And they also helped an awful lot with volunteers. The students came and empowered the volunteers and the volunteers could continue with the tasks they were doing ... Because we don't really have money to appoint the right quantity of personnel, the volunteers could come in and help us with that.

By involving and empowering volunteers to make a contribution in this community-based organisation, the sustainability of student activities was enhanced as volunteers could continue with projects once students left. Du Plessis and Van Dyk ${ }^{19}$ reiterate that enhancing community participation and connections can contribute to sustainability of service learning engagements. Furthermore, involving volunteers helped to address a very real need in terms of staff shortages, which is a need that prevails in many communitybased institutions"

In addition to the involvement and empowerment of volunteers in community-based organisations, facilitation of intergenerational and interracial connections within communities and establishing new connections with other organisations all contributed positively to community outcomes. Bringle and Steinberg ${ }^{14}$ correspondingly report that successful service learning projects help community organisations to form new connections with other organisations in the community, which they view as beneficial. In the same vein, Van Schalkwyk and Erasmus ${ }^{12}$ recommend that expanding connections should be a conscious effort for all stakeholders in service learning partnerships.

The enhanced connections referred to in this category were cultivated through multiple means, including direct facilitation of networking, mentoring to promote expanded connections, and the development of knowledge and skills among members of the community. Findings suggest that by enhancing connections, service learning projects may contribute to cultivating solidarity and agency in communities. Enhanced connections may also bring about a sense of common identity and purpose as an enabling by-product of such endeavours ${ }^{36}$; akin to Wilcock's ${ }^{37}$ notion of 'belonging'. 


\section{Enhanced confidence and dignity}

Participants articulated experiences where they were able to observe how community members gained in confidence through their interactions with occupational therapy service learning students. The following interview excerpt exemplifies this finding:

he is one of those cases where that child's whole personhood, his whole attitude, he grew in confidence. His parents from the home's side, there is a definite purposive intervention as a result of what happened at the school through the occupational [therapy student] ... His personality, his tidiness and in that child - he had a speech problem, but he is now babbling and overflowing with confidence.

Townsend et al. ${ }^{23}$ note that inspiring confidence is one of the check-points to facilitate a vision of possibilities - one of the occupational therapy enablement foundations. The Occupational Therapy Practive Framework (OTPF) isolates enhanced confidence as an outcome of occupational therapy that can be identified in clients' subjective impressions of the achievement of objectives ${ }^{20}$. The findings of this study indicate that, through occupational therapy service learning engagements, confidence was enhanced among community members.

In addition to enhanced confidence, participants also articulated experiences of enhanced dignity. The following participant summarised her overall impression of the effect of service learning in their community organisation as follows:

The elderly person was in the first place given more dignity. Because we could perhaps teach the uncle the right way to walk if he walked in the wrong way. So we gave the elderly person more dignity.

Human dignity is defined as "... a subjective experience of well-being contingent on the collective sum of (inter-)individual experiences of values" $38: 316$. The profession of occupational therapy values and attempts to foster human dignity ${ }^{17,22}$, and this is reflected in the findings of this study. However, if human dignity is viewed as the subjective experience of well-being of a person, the evidence here may only be viewed as anecdotal, as it was shared by the community representative, not the people themselves. Nonetheless, community representatives did perceive occupational therapy service learning engagements to enhance dignity as an outcome of occupational enablement endeavours.

\section{Enhanced occupational participation}

The overarching outcome of occupational therapy has been extrapolated as the enablement of occupation. Participants in this study relayed various ways in which they perceived occupational therapy service learning engagements to enhance occupational participation in communities, seen in the following quotation:

[The wellness programme] absolutely made us realise again that spiritually - we are in a rut sometimes - that one must be enriched spiritually. And through the spiritual enrichment we established a spiritual group where we now have Bible study every Tuesday morning before school. Despite the fact that we start each [morning] with the reading of scripture and prayer, we now have a Bible study group where one is really enriched spiritually. The second one is social. On a social level [we] ride bicycle. We hike together... we [have] functions ... where we just have fun. You know, having a picnic together. The other day I held a picnic for us. We sat on the grass and just babbled away.

Through implementing a wellness programme as part of a service learning project, occupational therapy students were able to catalyse a renewed focus on occupational domains such as spirituality and social interaction in the promotion of well-being. There is also evidence of community ownership of implementing strategies based on what students shared in the wellness programme - in the instance above, staff from the school themselves initiated activities such as Bible study and having picnics. These findings, therefore, indicate that occupational therapy service learning engagements do indeed have the potential to advance "health, well-being and participation in life" $32:$ S17-18 through enabling occupation in communities.
Finally, the following reflection from a participant during the interview provides a rich description of the value of occupational enablement as an outcome of service learning:

Because otherwise they sit here. They feel their children had rejected them. They feel the community had rejected them. They are too old to do something. And here come the students and they learn something from the elderly person. I think it means incredibly much to the elderly. A little upliftment, being a bit more human again, a bit - feeling that they belong. Feeling that they belong again. Yes. Yes, I think it means a lot to them.

Without any formal knowledge on occupational therapy theory, this participant was able to articulate the value of occupation through doing (e.g. teaching a student something), being ("being a bit more human again"), and belonging ("feeling that they belong again"), exemplifying Wilcock's ${ }^{37}$ renowned equation $d+b^{3}=$ sh (doing + being, becoming and belonging $=$ survival and health). Enhancing occupational participation, therefore, was perceived by participants in this study as a positive outcome of occupational therapy service learning.

\section{Non-realisation of partnership goals}

Participants in this study also identified project failure, or nonrealisation of partnership goals, as an outcome that they had experienced. The following comment by a participant indicates the frustration that could be experienced when partnership goals are not realised:

You know, if there is no continuity, it is bad, and then, like the mosaic project, the [students] started with it and now it has slowed down.

When the goals of the service learning engagement are not realised to the satisfaction of community partners, regardless of the reasons, communities and students alike experience disappointment. In extreme cases, it may even lead to what Netshandama calls "community fatigue" ${ }^{22: 80}$ and mistrust of the university in future engagements. Therefore, it is essential to address the potentially detrimental effects of the non-realisation of goals as a result of factors such as intermittent contact, proactively. Proactive strategies to combat non-realisation of goals are suggested by Janse van Rensburg ${ }^{39}$ and include collaborative planning, regular communication, fostering relationships, risk management, monitoring and measurement, and planning strategies for sustainability and hand-over.

\section{CONCLUSION AND RECOMMENDATIONS}

The findings of the study demonstrated that although there were some instances in which partnership goals were not realised, occupational therapy service learning engagements contributed to occupational enablement in communities. This came about through increasing community members' knowledge and skills, leading to a change in attitudes and practices, increasing access to resources and infrastructure, enhancing community, confidence, dignity and promoting occupational participation amongst community members. Occupational enablement in turn contributed toward occupational justice, as well as health and well-being for community members.

These empirically, inductively identified outcomes of service learning engagements that are based on the perceptions of community members can become valuable directives to future service learning. This could inform other community-based occupational therapy practitioners, of outcomes that could realistically and effectively be targeted during engagements with communities. They may also assist practitioners in designing outcome measures for community-based interventions that are based on perceptions of communities, rather than on those of the practitioners or those responsible for funding the intervention.

It is, however, important to note that due to its qualitative design, the findings of the study is limited to the specific context in which the research was conducted. Transferability to other settings should be judged on the basis of the contextual and interpretive 
descriptions offered in the presentation and discussion of the findings $^{28}$. The reader may also wish to access the original research report ${ }^{13}$ as the brevity of the information contained in the article is not sufficient to provide the depth of information required to make this judgment call. The temporal nature of the findings should also be declared. 'Perceptions' as investigated in this study are susceptable to changes over time as people's interpretations of experiences may change based on new information or different experiences. Perceptions may also change as the phenomenon itself (i.e. occupational therapy service learning engagements) evolves. A final limitation to consider is that the individually appraised, temporal and contextual nature of occupation renders occupational enablement a construct that cannot be described from the perceptions of anybody other than the persons 'doing' the occupation. Descriptions of occupational enablement of community members were articulated by community representatives on behalf of community members. Future studies should be undertaken to expand these secondary descriptions by describing occupational enablement from the perceptions of community members themselves. Further investigation into factors that contribute to sustainability of the outcomes of service learning engagements is also warranted. In addition, longitudinal research or long-term impact studies on the effect of occupational therapy service learning engagements in communities will strengthen the evidence-base in this subject area.

Service learning and other forms of community-based practice in occupational therapy is accompanied by a unique set of challenges. Individual efforts may often appear fragmented and insignificant. However, this complexity has taught us that the whole is greater than the sum of its parts. Each small act towards occupational enablement has the potential to transform the realities of people and communities towards greater health, well-being and justice.

\section{REFERENCES}

I. Concha, M. Occupational therapy at the University of the Witwatersrand - The past, the present and the future. South African Journal of Occupational Therapy. 20I4; 44(I): I-2.

2. Petersen N, Osman R. An introduction to service learning in South Africa. In: Service learning in South Africa. Osman R, Petersen N, editors. Cape Town: Oxford University Press Southern Africa; 20 I 3: 2-32.

3. Stanton TK, Erasmus MA. Inside out, outside in: A comparative analysis of service-learning's development in the United States and South Africa. Journal of Higher Education Outreach and Engagement. 2013; I7(I): 63-96.

4. Lorenzo T, Duncan M, Buchanan H, Alsop A. Practice and service learning in occupational therapy: Enhancing potential in context. West Sussex: Whurr Publishers; 2006.

5. Pretorius B, Bester J. Revisiting perceptions of fieldwork outcomes in the training of health professionals in an occupational therapy service-learning module. In: Service-learning in higher education: Paradigms and challenges. Moore M, Lin PL, editors. Indianapolis, IN: University of Indianapolis Press; 2009: 259-270.

6. Janse van Rensburg E, Du Toit SH. The value of a rural service learning experience for undergraduate occupational therapy students. South African Journal of Occupational Therapy. 2016; 46(I): 9-14. https://doi.org/I0.17159/2310-3833/2016/v46nla4.

7. Witchger Hansen A, Munoz J, Crist PA, Gupta J, Ideishi RI, Primeau LA, Tupe D. Service learning: Meaningful, community-centered professional skill development for occupational therapy students. Occupational Therapy in Health Care. 2007; 2I (I/2): 25-49. https://doi.org/I0.1080/j003v2In0I 03.

8. Reeb RN, Folger SF. Community outcomes of service learning. In: Research on service learning conceptual frameworks and assessment, Volume 2B: Communities, institutions and partnerships. Clayton $\mathrm{PH}$, Bringle RG, Hatcher JA, editors. Sterling: Stylus Publishing; 20I3: 389-4I8.

9. Bringle RG, Clayton PH, Hatcher JA. Research on service learning: An introduction. In: Research on service learning conceptual frameworks and assessment, Volume 2B: Communities, institutions and partnerships. Clayton PH, Bringle RG, Hatcher JA, editors. Sterling, VA: Stylus Publishing; 20I3: 3-26.
10. Butin DW. Service-learning in theory and practice: The future of community engagement in higher education. New York: Palgrave MacMillan; 2010. https://doi.org// 0.1353/rhe.2006.0025.

I I. Nduna NJ. The community voice on service-learning: A good practice guide for higher education. Education as Change. 2007; I I(3): 69-78. https://doi.org//0.1080/I6823200709487/80.

12. Van Schalkwyk F, Erasmus MA. Community participation in higher education service learning. Acta Academica. 20I I; 43(3): 57-82.

13. Janse van Rensburg, E. Enabling occupation through service learning: perceptions of community representatives in occupational therapy service learning engagements [unpublished dissertation]. Bloemfontein: University of the Free State; 2015. Available from: https://scholar.ufs.ac.za/handle/I I660/2233.

14. Bringle RG, Steinberg K. Educating for informed community involvement. American Journal of Community Psychology. 20 I0; 46(3/4): 428-44I. https://doi.org/I0.1007/s 10464-010-9340-y.

I5. Schindler VP. Community engagement: Outcomes for occupational therapy students, faculty and clients. Occupational Therapy International. 20I4; 2 I(2): 7I-80. https://doi.org/I0.I002/oti. I 364.

16. Olivier M, Oosthuizen L, Casteleijn D. Occupational therapy students' contribution towards enabling potential in a semi-rural community. Work. 2007; 29(I): 63-68.

17. Horowitz BP, Wong SD, Dechello K. Intergenerational service learning: To promote active aging, and occupational therapy gerontology practice. Gerontology and Geriatrics Education. 2010; 31 (I): 75-91. https://doi.org/I0.1080/02701960903578345.

18. Witchger Hansen A. Community partners' perspectives of community - university partnerships that support service-learning. Doctoral thesis. Duquesne University, Pittsburg, PA: ProQuest Dissertations Publishing; 2010. <http://search.proquest.com/ docview/728I6I439(I4 Sep 2017).

19. Du Plessis C, Van Dyk A. Integrating the community voice into service learning: Engaging with communities. In: Service learning in South Africa. Osman R, Petersen N, editors. Cape Town: Oxford University Press Southern Africa; 2013: 59-84.

20. American Occupational Therapy Association. Occupational therapy practice framework: Domain and process (3rd ed.). American Journal of Occupational Therapy. 2014; 68(Suppl I): SI-S48. https://doi.org//0.50|4/ajot.2014.68sl.

21. Polatajko H, Davis J, Stewart D, Cantin N, Amoroso B, Purdie L, Zimmerman D. Specifying the domain of concern: Occupation as core. In: Enabling occupation II: Advancing an occupational therapy vision for health, well-being and justice through occupation, 2nd edition. Townsend EA, Polatajko H, editors. Ottowa: CAOT Publications ACE; 20I3: I3-36.

22. Creek J. Occupational therapy defined as a complex intervention. London: College of Occupational Therapists; 2003.

23. Townsend EA, Beagan B, Kumas-Tan Z, Versnel J, Iwama M, Landry J, Brown J. Enabling: Occupational therapy's core competency. In: Enabling occupation II: Advancing an occupational therapy vision for health, well-being and justice through occupation, 2nd edition. Townsend EA, Polatajko H, editors. Ottowa: CAOT Publications ACE; 20I3: 87-I33.

24. Strydom H, Delport CSL. Sampling and pilot study in qualitative research. In: Research at Grass Roots: For the social sciences and human service professions, $4^{\text {th }}$ edition. De Vos AS, Strydom H, Fouché CB, Delport CSL, editors. Pretoria: Van Schaik Publishers; 2010: 390-396.

25. Creswell JW. Qualitative inquiry and research design: Choosing among five approaches.Thousand Oaks, CA: SAGE Publications; 2013.

26. Saldaña J. The coding manual for qualitative researchers. London: SAGE Publications; 2009.

27. Mertens DM. Research and evaluation in education and psychology (3rd ed.). Thousand Oaks, CA: SAGE Publications; 2010.

28. Polit DF, Beck CT. Essentials of nursing research: Methods, appraisal and utilization (6th ed.). Philadelphia, PA: Lippincott Williams Wilkins; 2006.

29. Creswell JW. Research design: Qualitative, quantitative, and mixed methods approaches, $3^{\text {rd }}$ edition. Thousand Oaks, CA: SAGE Publications; 2009.

30. Braveman BH, Otr L, Helfrich CA, Fisher GS. Developing and maintaining community partnerships within "a scholarship of practice". 
Education for Occupational Therapy in Health Care. 200 I; 15(I): I09-I25. https://doi.org/I0.1300/j003vl5n0I_I2.

31. Scaffa ME. Community-based practice: Occupation in context. In: Occupational therapy in community-based practice settings. Scaffa ME, editor. Philadelphia, PA: F.A. Davis Company; 200I: 3-I8.

32. Netshandama V. Quality partnerships: The community stakeholder's view. Gateways: International Journal of Community Research and Engagement. 20I0; 3: 70-87.

https://doi.org//0.5 I30/ijcre.v3i0.154I.

33. Brower $\mathrm{HH}$. Sustainable development through service learning: a pedagogical framework and case example in a third world context. Academy of Management Learning and Education. 20I I; 10(I): 58-76. https://doi.org/I0.5465/amle. I0.I.zqr58.

34. Durocher E, Gibson BE, Rappolt S. Occupational justice: A conceptual review. Journal of Occupational Science. 20 I 3; 2 I (4): 4I 8-430. https://doi.org/I0.1080/I442759I.2013.775692.

35. Suarez-Balcazar Y, Hammel J, Helfrich C, Thomas J, Wilson T, Head-Ball D. A model of university-community partnerships for occupational therapy scholarship and practice. Occupational Therapy in Health Care. 2005; 19(I/2): 47-70.

https://doi.org/I0.1080/j003vI9n0I_05.

36. Galheigo SM. Occupational therapy in the social field: Clarifying concepts and ideas. In: Occupational therapy without borders: Learning from the spirit of survivors. Kronenberg F, Algado SS, Pollard N, editors. London: Elsevier; 2005: 87-98.

37. Wilcock AA. Occupation and health: Are they one and the same? Journal of Occupational Science. 2007; I4(I): 3-8. https://doi.org/10.1080/14427591.2007.9686577.

38. Mattson DJ, Clark SG. Human dignity in concept and practice. Policy Sciences. 20II; 44(4): 303-319. https://doi.org/I0.1007/s I |077-010-9|24-0.

39. Janse van Rensburg E. A framework for occupational enablement to facilitate social change in community practice. Canadian Journal of Occupational Therapy. 2018; 85(4): 318-329.

https://doi.org/I0.1 I77/00084I74I8805784.

\section{Corresponding Author}

\section{Elize Janse van Rensburg}

JanseVanRensburgE@ufs.ac.za 